\title{
Governor and course leaders' reflections on HE in FE: strategic ambition and curriculum practice in two large colleges in England
}

\author{
Jaswinder K. Dhillon \& Jon Bentley
}

To cite this article: Jaswinder K. Dhillon \& Jon Bentley (2016) Governor and course leaders' reflections on HE in FE: strategic ambition and curriculum practice in two large colleges in England, Research in Post-Compulsory Education, 21:1-2, 137-150, DOI: 10.1080/13596748.2015.1125668

To link to this article: http://dx.doi.org/10.1080/13596748.2015.1125668

Published online: 03 Mar 2016.

Submit your article to this journal $₫$

Џll Article views: 43

View related articles $\sqsubset$

View Crossmark data $\asymp$ 


\title{
Governor and course leaders' reflections on HE in FE: strategic ambition and curriculum practice in two large colleges in England
}

\author{
Jaswinder K. Dhillon ${ }^{\mathrm{a} *}$ and Jon Bentley ${ }^{\mathrm{b}}$ \\ ${ }^{a}$ Institute of Education, University of Worcester, Worcester, UK; ${ }^{b}$ Part-Time Doctoral Student \\ and Full-Time Lecturer
}

(Received 21 September 2015; accepted 18 November 2015)

\begin{abstract}
In the turbulent 'dog eat dog' environment of the learning and skills sector in England the provision and expansion of higher education taught in further education colleges (HE in FE) offers potential opportunities for greater diversification of higher education. However, it also presents significant challenges, which include developing an HE culture, managing shifting partnerships, and ensuring the curriculum meets benchmarks for quality and standards of provision. This article uses principles of appreciative enquiry to explore the experience, potential and challenge of growing $\mathrm{HE}$ in FE in two large colleges, one located in an urban area and the other in a rural region of central England. Both colleges reflect similarities and differences in their strategy and delivery of HE in FE and neither uses the term 'further' to describe its provision. This shift in branding reflects the strategic ambitions of governors and senior leaders as the curriculum offer is no longer general 'further education' but much more diverse, and includes HE courses delivered in partnership with four universities. Using data from governing bodies, cross-college committees and course leaders we reflect on the spaces and places for growing HE in FE and the challenges it poses for governors, leaders, tutors and students.
\end{abstract}

Keywords: Higher education; colleges; strategies; challenges; curriculum

\section{Introduction}

The government of the United Kingdom has encouraged the development and growth of higher education taught in further education colleges (HE in FE) for its potential to widen participation by making higher education (HE) more accessible to individuals and groups that are hard to reach through traditional university education. In 2013/14 there were 189,040 HE enrolments at further education colleges compared to 186,565 in 2012/13 (Higher Education Statistics Agency [HESA] 2015). Although the range of settings and the types of HE available to students has increased, the three-year degree taught on a large university campus still remains the dominant form of HE provision, with 2,299,355 enrolments in 2013/14 (HESA 2015). For some individuals and groups this may be a daunting prospect and so the possibility of undertaking a degree in a familiar institution and studying in smaller groups, as in $\mathrm{HE}$ in $\mathrm{FE}$ provision, offers an attractive alternative to a large campus

\footnotetext{
*Corresponding author. Email: j.dhillon@worc.ac.uk
} 
university where they may be lost in a mass of hundreds of students doing the same course. There are of course economic reasons for encouraging HE in FE, which are considered below, and opposing views about the parity and quality of HE experience for students who undertake their HE learning in a college rather than a university, which are reflected in our data. For the colleges themselves, HE work offers a valuable alternative source of income and engaging higher-level work for teaching staff as they struggle with the effects of austerity and savage government cuts to the funding of their sector of education and training.

\section{Policy context}

In July 2015 the recently elected Conservative government announced a $£ 60$ million cut to funding for the sector, contributing 13\% towards the Department for Business, Innovation \& Skills (BIS) savings of $£ 450$ million announced in the July budget (Boles 2015). BIS is the government department with responsibility for funding the learning and skills sector which includes further education colleges. In addition to cuts to funding current provision in colleges, which included a $3.9 \%$ cut to adult learning for 2015-16, the government announced a national programme of areabased reviews as the basis of a restructuring of post-16 education and training. Area-based reviews are intended to assess the resilience of colleges and their capacity to meet local market needs. In its policy paper setting out the process for the review, the government states that

major reform of post-16 education and training institutions is now necessary, in a way which also addresses the significant financial pressures on institutions including a declining 16-19 population and the need to maintain very tight fiscal discipline in order to tackle the deficit. (BIS 2015, 3)

At the time of writing this article, the national programme of area-based reviews had just started and the experiences of the two colleges which form the basis of our reflections on HE in FE were anxiously awaiting their area review. The government's determination to focus funding on apprenticeships over other forms of provision is very clearly set out in the letter by the chief executive of the Skills Funding Agency (Lauener 2015) to governing bodies and college principals. The letter and other documents discussed above (BIS 2015; Boles 2015) reflect the policy context in which colleges have to operate and the financial pressures which impact on their strategic and operational direction. It is in this context that HE in FE provision takes place and debates about its potential and challenges need to be understood, as it is a business rather than educational model which has to drive governance, leadership and the curriculum offer in colleges.

$\mathrm{HE}$ in FE is a relatively small part of the work of further education colleges, typically around $2 \%$ of learners, as illustrated by the two colleges we discuss in this article. In the next section we review research literature on HE in FE highlighting the potential and benefits of the provision and the challenges it poses for colleges and tutors in providing an educational environment which has parity with that available to students who undertake their learning in universities. We begin by considering economic reasons for undertaking $\mathrm{HE}$ in FE. 


\section{Literature review}

The promotion of HE in FE is motivated by economic as well as educational reasons. The cost of undertaking a course is considerably lower and marketed by colleges as representing 'great value for money'. Most universities in England charge tuition fees of $£ 9000$ per year for their courses, in addition to which students need to pay for accommodation, travel, food and other living expenses. The average cost of living in the UK is around £12,000 (Playdon 2015) and so when combined with the $£ 9000$ tuition fees the cost of undertaking a course at a university rises to $£ 21,000$ whilst the cost in a college can be under $£ 5000$ per year, excluding cost of living expenses. For example, the advertised fee on a college website for 2015-16 for a Higher National Certificate/Diploma (HNC/D) course is $£ 4800$ whilst the fee for $\mathrm{HNC/D}$ at a university is $£ 8200$. Furthermore, by studying for an HE course at a local college rather than a university most students will save on accommodation and travel costs. These figures are quite conservative estimates for HE courses as costs can be much higher in some areas, such as London, and tuition fees are also higher for international students. The increasing burden of student debt for HE students is a regular feature of press and media coverage and is affirmed by recent research undertaken by the Institute for Fiscal Studies, commissioned by the Sutton Trust, which found that students will leave university with an average debt of $£ 44,000$ (Crawford and Jin 2014). Thus, the potential of HE in FE has economic appeal.

The educational attraction of $\mathrm{HE}$ in FE is well captured in the statement 'choose small classes, personalised tuition and a genuinely welcoming atmosphere' (College website). This suggests cosy places and spaces for learning rather than anonymous buildings with academic staff intent on completing their 'world leading research' than on teaching undergraduate students. These contrasting organisational cultures and associated expectations constitute sources of contention for the quality and equity of students' experience of HE, as is revealed in the data we present on strategic ambition and the curriculum in practice in colleges which provide $\mathrm{HE}$ in FE. Creasy (2013) is critical of the provision of HE in FE and focuses on the question of what is meant by HE, concluding 'that the student experience will be different' (51) when HE is taught in colleges. His central argument rests on the premise that a key difference between $\mathrm{HE}$ and $\mathrm{FE}$ is the expectation that staff engage in research and scholarly activity. Our data indicate that Creasy's view may no longer be tenable as colleges are expecting staff who teach $\mathrm{HE}$ in FE courses to undertake research to inform their pedagogic practice as well as offering students dedicated HE facilities (see Table 1).

The culture of HE may be difficult to develop in colleges and various studies have highlighted the cultural differences which exist between HE and FE (Burkill, Rodway Dyer, and Stone 2008; Feather 2011; Harwood and Harwood 2004; Orr 2013; Parry 2012). This body of research includes studies that evidence the challenges facing students when they transition between FE and HE institutions for 'top-up' (Bathmaker et al. 2008; Greenbank 2007; Knox 2005; Leese 2010; Pike and Harrison 2011; Winter and Dismore 2010). 'Top-up' is the process of completing the final years of a course, usually a degree at the partner university whilst undertaking the first and second year at a college. The 'transition' both academically and psychologically contributes to the quality of students' experience of HE study and can be variable. For example, Greenbank $(2007,96)$ found that students' com- 


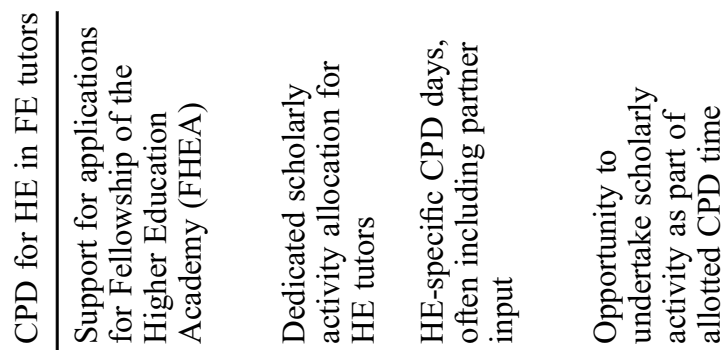

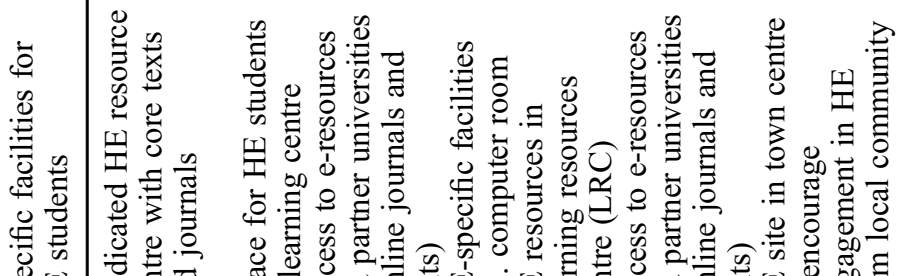

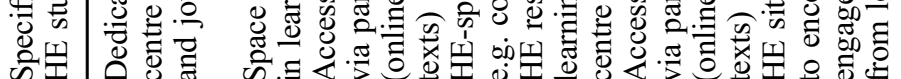

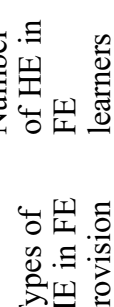

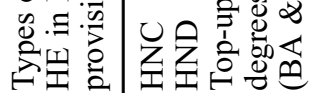
$\stackrel{2}{2}$

光星兽兽

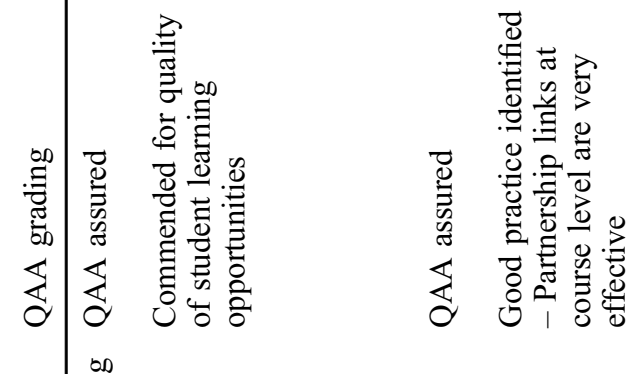

: 를

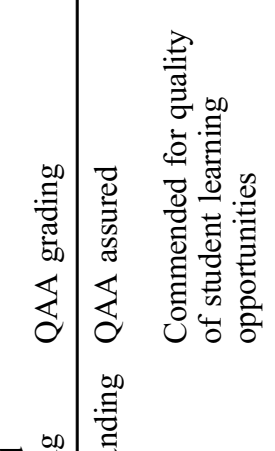

7
8
0

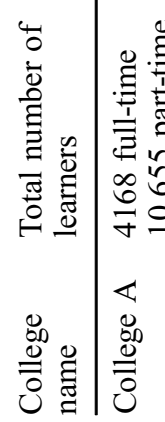

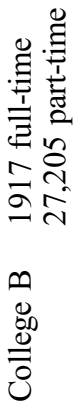


ments on their FE experience included 'sometimes you can tell lecturers only know the basics' in a study of the transition from foundation to honours degree.

In addition to developing an $\mathrm{HE}$ culture, the provision of $\mathrm{HE}$ in $\mathrm{FE}$ involves managing shifting partnerships with universities at both strategic and operational levels. Colleges deliver, and in some cases award HE qualifications, but they are accredited and quality assured by partner universities and the Quality Assurance Agency for Higher Education (QAA). Research on partnerships between colleges and universities has identified the role of power and politics, and the less tangible but equally important characteristics of shared values, trust and networks in developing, managing and leading cross-sector partnerships (Billet et al. 2007; Cardini 2006; Dhillon 2007, 2013; Elliott 2015). These relationships pose new challenges in the policy environment discussed in the preceding section of this article. In particular, the dominance of the business model for growing HE in FE means that colleges are working in partnership arrangements with a larger number of universities that are geographically more distant from their college campuses. Ambitious college leaders are now seeking strategic partnerships with a wider range of universities rather than focusing on the nearest university, which they would have done in the past. The colleges exemplified in our study are engaged in developing and extending their provision of $\mathrm{HE}$ in FE by working in partnership with six universities across England and Wales. In the following section we discuss the methodological approach used in this study and our sources of data.

\section{Methodological approach and data sources}

Our methodological approach uses principles of appreciative inquiry which involve a focus 'not on problems, failings and deficits but on strengths, successes, opportunities and innovations' (Kadi-Hanifi et al. 2014, 585). We do not ignore issues and problems in the sector or in our sample colleges but as reflective practitioners (Schon 1991) and reflexive researchers (Etherington 2004) working in HE and FE focus on the potential and challenges of providing high-quality $\mathrm{HE}$ in FE. Our purposive sample of a large inner city urban college (College A) and a large rural college (College B) located in the Midlands of England exemplify similarities and differences as 'general further education colleges' which is how they are classified by policymakers and inspectors of post-16 education and training in England. The quality of education and training provided by colleges of this nature is inspected by the Office for Standards in Education, Children's Services and Skills (Ofsted) who 'inspect and regulate services that care for children and young people, and services providing education and skills for learners of all ages' (Office for Standards in Education, Children's Services and Skills [Ofsted] 2015a). Following an inspection visit to a school, college or other provider of skills training, Ofsted are responsible for 'publishing reports of our findings so they can be used to improve the overall quality of education and training'(Ofsted 2015b). These reports give a grading for the quality of provision and we have chosen colleges which have been graded as 'good' or 'outstanding' by Ofsted as our focus is on strengths, successes, opportunities and innovations in the sector.

The two colleges are also highly rated for the quality of their HE in FE provision. HE provision is audited by the Quality Assurance Agency for Higher Education (QAA) which is 'the independent body entrusted with monitoring and advising on standards and quality in UK higher education' (QAA 2015a). The QAA regularly 
'review higher education providers to check whether they meet agreed UK expectations' (QAA 2015b) through a process called evidence-based external review. Following a review the QAA issue a report on the quality and standards of $\mathrm{HE}$ at the provider (university or college) which is publicly available, like an Ofsted report. Thus, HE in FE provision is subject to the same standards as HE in universities. In its last QAA review, College A was commended for the quality of student learning opportunities and College B for its effective partnership links at course level.

We have used Ofsted and QAA data which is publicly available to summarise similarities and differences between the two colleges we have selected as our focus to maintain anonymity and confidentiality, in line with ethical guidelines for research (British Educational Research Association [BERA] 2011). These similarities and differences are summarised in Table 1, which gives profile data on College A and College B.

Our other sources of data include a search of college and university websites, statements issued by government departments and funding agencies, such as the Department for Business, Innovation \& Skills, the Skills Funding Agency, and our personal reflections and observations on $\mathrm{HE}$ in FE, as implemented in the two colleges. We are both privy to insider knowledge as researchers and practitioners but have decided not to use any data which is not publicly available in documents intended for the wider public. Our reflections on strategic ambition and curriculum practice, presented below, are personal accounts and observations and do not represent the views of any other individual associated with the colleges. We begin with the strategic perspectives of governors and senior college leaders and then focus on the curriculum level through the perspectives of course leaders of HE in FE courses.

\section{A governor's observations of strategic ambition: a walk through College A}

A walk through College A illustrates strategic ambition and organisational aspiration for growing $\mathrm{HE}$ in $\mathrm{FE}$ and is written from the perspective of a newly appointed governor at College A, a large inner city urban college graded by Ofsted as outstanding at its last inspection. There are 11 other colleges within a 15-mile radius of College A. At the time of inspection, the college had 4168 full-time and 10,655 part-time learners (Ofsted 2013) ${ }^{1}$ with a high proportion of learners from neighbourhoods of multiple deprivation and the proportion of students achieving five $\mathrm{A}^{*}$ to $\mathrm{C}$ grades at GSCE, including English and mathematics, below national averages. The HE in FE provision at College A consists of Higher National Certificate (HNC), Higher National Diploma (HND) and BA and BSc courses which involve working in partnership with four universities. These include BA Visual Communication, BA Fashion and Textiles, BA Business Studies and BSc Computing. The observations of a governor given below attempt to portray the organisational culture and strategic ambitions of College A, as a vocational college with ambitions for growing HE in FE:

As you walk into the atrium which houses the main reception of the college, you are immediately struck by the vibrancy of the college; students are running a charity fund raising event, security guards are walking around keeping an eye on things without being obtrusive and tutors and students are sitting around the cafe area, drinking Costa coffee, chatting, texting and making their way to classes. The walls display inspirational quotes from educators, writers, poets and thinkers, for example, 'If you can imagine it, you can achieve it; if you can dream it, you can become it.' These 
messages are complemented by photographs of recent college events, awards and trophies that recognise college achievements and boards that display photographs of governors and staff. The logos of partner organisations displayed in reception include market leading organisations and providers of training to industry standards.

One corner of the atrium leads to the 'Little Professors' nursery, another to the college training restaurant which is opposite the customer advice and support centre. This hub of activity at the heart of the college does not feel like a 'further' education college or large training organisation, which many colleges have become, but much more like an educational organisation which aspires to provide the best opportunities for all the learners that walk through the doors. This organisational culture is well captured by the vision and values of the college, positioned as being 'uniquely and proudly vocational' and set out in five strategic ambitions which are displayed all around the buildings. It is of course, easy to display statements about vision and values in organisations and much more challenging to take all staff with you in leadership and management practice. This is something that College A has managed to achieve, at least according to its Ofsted grading which is outstanding for the effectiveness of leadership and management. The most recent Ofsted report states that leaders, managers and governors have an ambitious vision for the college and its students. This is well articulated in the college's vision statement which declares:

Our greatest passion is unleashing the potential of individuals, communities and businesses; our greatest legacy is the talent of our students: skilled, professional and enterprising.

To a newly appointed governor, it is evident that the strategic ambition and organisational aspirations of the college are deeply felt and shared by the senior management team and the whole of the governing body. The governing body consists of 15 governors drawn from a range of organisations and backgrounds and representatives of the senior leadership and management team of the college. The extract below from a meeting of 'the corporation', which has overall legal responsibility for the activities of the college, illustrates the passion of members of the governing body and their aspirational ambitions for learners and the strategic direction of the college:

'Because if $w e^{2}$ don't do it who will - the learners have been failed by the schools in the area so we have to provide the best chances for them to do well and get the skills they need to find work or carry on with further and higher education and training.' (Senior leader, College A)

'I'm really pleased to hear that as we need people with engineering skills and we must provide the best skills training in the region.' (College governor and CEO of a major engineering company)

'I want to congratulate the senior leadership team on all the hard work they're doing ... our principal is excellent and all the team work relentlessly to get the best for learners and we as governors should be proud of the achievements of our college ... I'm really proud to be associated with [name of college] College ... when I drive past the college I am proud to say I am a governor at ... [name of college].' (Chair of governors, College A)

'We will become the University of $X$ and compete directly with Y [geographically the nearest university], we should put up a board in our new building and call it the University of ... We can do that I've checked the regulations ... that way we will attract more HE students because at the moment many parents and students have no idea that they can do HE courses with us here at the college rather than going away to university.' (Senior manager, College A)

The number of learners on HE in FE courses in College A is currently around 200 learners, a relatively small number in relation to the total number of college learners, but as the extract above illustrates HE provision is regarded as being very important 
by senior managers. Senior management teams and curriculum leaders at the college are keenly developing strategies for growing $\mathrm{HE}$ in $\mathrm{FE}$ for both economic and educational reasons.

\section{Strategies for developing the $\mathrm{HE}$ culture and growing $\mathrm{HE}$ in $\mathrm{FE}$ at College $A$}

On the economic front, national cuts to funding adult learning, which we discussed earlier in the policy context section of the article, make HE in FE an attractive income stream with opportunities to diversify the curriculum offer and so grow provision. On the educational front, the potential of teaching HE courses offers tutors a little more flexibility and opportunity to exercise creativity in their professional practice; a welcome alternative to governments' relentless focus on apprenticeships and skills for the economy. This was particularly noticeable when the head of HE courses at College A spoke about students' satisfaction with the courses on offer and the tutors' engagement with professional development activities designed to support HE in FE. The college has introduced continuing professional development (CPD) for HE in FE tutors, as shown on Table 1. This includes an allocation of time on their workload for scholarly activity. Individual tutors and HE in FE teams may include empirical research projects or develop, trial and evaluate innovations in teaching/learning with their students and colleagues as part of these CPD activities. This work is also supported by a central unit for digital learning, learning mentors and champions who work with staff across all curriculum areas.

College A has also developed symbolic aspects of an aspirational and ambitious HE culture. It holds an annual graduation ceremony for HE courses which mirrors graduation ceremonies held at universities, has developed a profile of graduate attributes and a graduate certificate which celebrates students' achievements. The college graduate certificate is produced as a high-quality document 'to be proud of' and is awarded for outstanding achievement. In addition, the college hosts HE open days and has specific website space to market its HE in FE provision.

Externally, the college has well-established partnerships with four universities and is an outward-looking organisation in terms of building new partnerships with more geographically distant universities. It is aspirational in other aspects of education and training provision and aims to become a national leader / centre of excellence for vocational education as well as providing excellent learning for local students. However, all is not rosy in every respect and the college has had discipline problems which have needed an increased presence of security guards and staff visibility in common areas and greater vigilance following the Prevent strategy, which is the government's response to threats of terrorism. These reflections provide an insight into the opportunities and challenges of providing $\mathrm{HE}$ in colleges from a strategic perspective and we now present a perspective from the operational level of $\mathrm{HE}$ in FE curriculum practice.

\section{A course leader's reflection on curriculum practice: the experience at College B}

A course leader's reflection on curriculum practice illustrates the implementation, or delivery as it is often described, of HE in FE. It is written from the perspective of a course leader of HE students at College B, which is located in a rural region and the only large general further education college in the area, graded by Ofsted as good at its last inspection. At that time of inspection, the college had 1917 full-time and 
27,205 part-time learners (Ofsted 2010) ${ }^{3}$ with a substantial proportion of learners from wards ranked in the top $10 \%$ for multiple deprivation, with five or more GCSE $\mathrm{A}^{*}-\mathrm{C}$ grades including English and mathematics below national averages. College B's mission statement begins 'Where great futures begin and every learner matters' and the college charter claims to provide outstanding quality of provision, outstanding advice guidance and support and opportunities for learner involvement. The HE in FE provision includes Higher National Certificate (HNC) Higher National Diploma (HND) and foundation degrees in partnership with two universities. The reflections below are from a course tutor who teaches on a HND course which includes visits to the partner university.

This reflection is drawn from my experiences as a course leader for a group of HE students studying in College B. The cohort of students undertaking this course could be grouped together in terms of their general characteristics. They are students who have previously studied at level 3 within College B, of similar age (18- to 19-year-olds), first generation HE students, limited knowledge and understanding of HE study and awards. These students could be viewed as being 'non-traditional' and as a product of widening participation agendas (Department for Education and Skills [DfES] 2003). The course described here is taught solely at College B's campus, by college staff. Staff have a dual role within the college, teaching both HE and FE programmes. The college environment has limited HE-specific resources but includes a selection of advanced reading material in the learning resources centre (LRC), and a specific HE room which includes computer facilities and a kitchenette.

Within this primarily FE environment I have observed students do not routinely develop a strong identity as an HE student. I often fail to observe any meaningful changes in attitude, behaviour or aspiration with students finding the kind of autonomy which is so essential to positive HE experience and progress challenging. In a dual role as module leader, I often note that these students engage with limited further reading, leave their work until just before deadlines and lack enthusiasm for self-development. This is supported by previous research which suggests students are now accessing HE in nuanced ways (Leese 2010). McInnes (2003) has suggested students expect HE to fit around their lives. Byrne and Flood (2005) suggest 70\% of students intend to work part time, to such an extent the distinction between full- and part-time study is blurred (Winn 2002). Geographically, College B is 40 miles from the HE partner institution. Although almost all communication is electronic and a full suite of e-resources is available, this distance limits the physical access students have to the HE campus and therefore I believe influences the students' identity as being part of the HE community at the partner institute and therefore may detract from a full $\mathrm{HE}$ experience. On average students from College B are taken to the HE partner campus once per semester. But while on these visits I have observed thought-provoking responses from students.

\section{Visits to partner institution}

When students from this course visit the partner university campus they are given a glimpse of HE culture and campus life. Students are in different surroundings, interacting with a much broader range of students and staff, and exposed to new experiences. I would describe the students' initial reaction to the university campus as 'caught in the head lights' with an equal mix of hedonism. They are seemingly impressed by the facilities whilst being intimidated by the number of other students around them. They conform to expectations such as listening to presentations and speakers, manage their time effectively and show an enthusiasm for learning (which is not always the case while at the FE campus). They seem to contextualise their course and the purpose of higher education in a more accelerated manner than when on the FE campus. As course leader this leads me to question what it is about this experience which promotes these changes, how can the course team continue this wave of engagement when the course returns to its FE environment? (Course tutor reflections, September 2015) 
This is a challenge for HE in FE provision as the change in environment appears to have an effect on students' approaches to learning. This is congruent with suggestions that wider issues such as resource changes or site location influence students' perceptions of learning environment (Postlethwaite and Maull 2007). While on visits to the partner university learners demonstrate what Marton and Saljo (1976) describe as deep approaches to learning in contrast to the prevailing surface approach which many students demonstrate when in their FE environment. The reasons underpinning this change of approach may not be clear but demonstrates the students' capacity to alter their approach as their perceptions of the environment change. As Biggs (2012, 40) suggests, a deep approach to learning is desirable, despite higher proportions of students needing help to 'achieve the same levels of understanding that their more committed colleagues achieve spontaneously'. A deep approach to learning is characterised by a commitment to learn, understand and seek meaning in knowledge resulting in a more critical position (Hall, Ramsey, and Raven 2004) and is considered to be an aim of HE courses.

\section{Discussion and concluding remarks}

Our reflections on HE in FE provision based on our experience of observing the implementation of HE courses in two large colleges in England reveal the opportunities and challenges for growing HE in FE. For many colleges, HE in FE is a very small part of their curriculum offer but is being vigorously promoted for both economic and educational reasons. At a strategic level it is both an additional source of income for the college and a means of branding a distinctive and aspirational culture for the organisation. In a policy context where the sector is dealing with severe cuts to funding which left almost half of all colleges in England in financial deficit in 2013-14, experiencing what has been termed a 'meltdown' (Coughlan 2015), the prospect of income streams from HE courses presents a welcome business opportunity. Our data from College A provides an insight into the ambitious aspirations of some senior college leaders to grow their HE courses and rival the neighbouring university. This strategic ambition is driven by both business and educational values; the determination to provide high-quality learning for all learners at the college and to remain in good financial standing. As our data from a meeting of the corporation at College A has shown, the governors and senior management team are all passionate about providing the best education and training opportunities for learners who have been 'failed' by the schools in the area.

The balance of decision-making at strategic level has shifted as colleges are businesses with budgets running into millions of pounds and the finance and audit committee in a college is as, if not more important, than the learning and quality committee which oversees the quality and standards of the courses on offer. This shift is reflected in the make-up of senior management teams as former accountants are in leadership posts rather than vocational/educational lecturers with teaching and management experience of college curricula. The business-driven model where financial sustainability has to be balanced with local post-16 education and training needs and national government policies poses huge challenges for individual colleges as well as the sector as a whole. However, our evidence and experience indicates some optimism in that governors, senior management teams, course leaders and tutors are determined to provide education and training, including $\mathrm{HE}$ in $\mathrm{FE}$, 
which gives learners the best chances of finding employment and leading, in the words of a governor who was CEO of an engineering company, 'fulfilling lives'.

In terms of students' achievements and learning journeys, HE in FE offers opportunities for undertaking HE-level learning for students who may for various reasons not be in a position to study at university. HE in FE students may be choosing to study near their family home due to other factors which impact on their lives, such as caring responsibilities, finances, part-time work, as well as familiarity with the learning environment of a college where they may already be students. Furthermore, a 'savvy' student may be aware that a top-up pathway would enable them to complete an honours degree within three years, the same as a student who had achieved much higher entry requirements and entered HE directly at a university. The capacity of colleges to provide smaller class sizes, personalise learning and provide individualised support is greater than in a university. For example, the QAA report on the HE in FE provision at College A commended the college for the quality of student learning opportunities (see Table 1). The tuition fees for studying HE in a college rather than a university are also much lower, as shown by data presented earlier, so the quality of students' learning experience may be better and the cost for them lower. However, they may not experience the same HE culture as they would if attending a university.

The capacity of colleges to provide an HE culture has been the subject of considerable research and debate and remains a challenge when HE is only a small part of the provision of further education colleges. University-based academics have commented on the lack of 'HEness' in college-based provision of $\mathrm{HE}$ and our data reveal the challenges in curriculum practice of nurturing aspects of HE-level study, such as independence in learning, critical thinking and deep rather than surface approaches to learning. However, our evidence, experience and observations do not support Creasy's (2013) view that HE in FE is 'HE lite'. At the strategic level, ambitious colleges are developing policies and practices, such as the ones summarised in Table 1, which are equivalent to ones found in universities; for example, dedicated time for scholarly activity for their HE tutors, support for membership of the Higher Education Academy (HEA), and encouraging pedagogic research and innovation to inform teaching and learning. At the level of curriculum practice, course leaders and course teams are engaging with partner universities to support and nurture students, and through events, such as visits to partner institutions, to broaden student's perspective and aspirations. The QQA review of HE in FE provision at College B affirmed that partnership links at course level are very effective and identified them as an area of good practice, see Table 1.

Colleges, such as College A and College B, not only provide opportunities for learners to study $\mathrm{HE}$ in $\mathrm{FE}$ with them but also provide pathways for students to gain qualifications for direct entry to study at universities, not just the ones with whom they have partnership arrangements for the delivery of HE-level learning in their own college. This broader aspect of raising aspirations, through events such as visits to university campuses, gives learners who may not have had the confidence to consider HE an opportunity to contemplate HE-level study, either in a college or a university. Such colleges are also well placed to develop other forms of HE learning, including higher apprenticeships and professional courses, as a search of their websites will show. For learners for whom the rationale for HE study is influenced by future potential earnings and access to professional employment rather than learning 
for its own sake, such opportunities may be more appealing than traditional campusbased university courses.

In conclusion, our reflections based on the data we have presented and our experience as $\mathrm{HE}$ and FE practitioners and researchers explore the opportunities and challenges of HE in FE provision as implemented in two large colleges in England. The two colleges are not representative of all further education colleges in England but reflect similar characteristics in terms of size, number of HE in FE learners, region of England, as well as differences in terms of urban and rural locations, number of partner universities with whom they have formal partnership agreements and Ofsted and QAA ratings. We have presented opportunities and challenges as experienced at the strategic level by governing bodies and at the curriculum level by course leaders and tutors delivering HE courses in the two colleges. Our reflections and analysis show that HE in FE presents opportunities at strategic and curriculum levels for both economic and educational reasons for the institutions involved and the potential learners. The ambitious aspirational culture seen in College A at strategic level and the practicalities of teaching and learning at course level seen through the eyes of a course leader at College $\mathrm{B}$ convince us that $\mathrm{HE}$ in $\mathrm{FE}$ is a valuable and important part of the provision of colleges despite the challenges of developing an HE culture that is comparable to a university campus. The criticism that HE in FE is 'HE lite' needs to consider the motivations of learners and the diversity of learning experiences available to students at different types of universities. It may well be the case that the learning experience at some universities is 'HE lite' if HEness is taken to mean engagement in research and scholarly activity by all academic staff. As our data show, colleges are taking measures to introduce these aspects of HEness into their workforce development strategies and looking forward to growing their HE courses.

\section{Disclosure statement}

No potential conflict of interest was reported by the authors.

\section{Notes}

1. We have used the last inspection report for context and background information for the college, rather than other documents, such as self-assessment reports, on the college website. This means that the learner numbers given in the article may not be the most update figures.

2. The use of italic font indicates emphasis by the speaker.

3. We have used the last inspection report for context and background information for the college, rather than other documents, such as self-assessment reports, on the college website. This means that the learner numbers given in the article may not be the most update figures.

\section{Notes on contributors}

Jaswinder K. Dhillon is professor of education at the University of Worcester. She has worked in adult, further and higher education as a lecturer, teacher educator and researcher and is a governor at a school and a college. Her research interests include further and higher education, partnership working and students' experience of education and training.

Jon Bentley is a part-time doctoral student and a full-time lecturer in a further education college. His research interests are student agency, experience, and transition. 


\section{References}

Bathmaker, A. M., G. Brooks, G. Parry, and D. Smith. 2008. "Dual-Sector Further and Higher Education: Policies, Organisations and Students in Transition." Research Papers in Education 23 (2): 125-137.

BERA (British Educational Research Association). 2011. Ethical Guidelines for Educational Research. London: British Educational Research Association. https:/www.bera.ac.uk/wpcontent/uploads/2014/02/BERA-Ethical-Guidelines-2011.pdf?noredirect=1

Biggs, J. 2012. "What the Student Does: Teaching for Enhanced Learning." Higher Education Research \& Development 31 (1): 39-55.

Billet, S., C. Ovens, A. Clemens, and T. Seddon. 2007. "Collaborative Working and Contested Practices: Forming, Developing and Sustaining Social Partnerships in Education." Journal of Education Policy 22 (6): 637-656.

BIS. 2015. Reviewing Post-16 Education and Training Institutions. London. Department of Business Innovation and Skills. https://www.gov.uk/government/uploads/system/uploads/ attachment_data/file/446516/BIS-15-433-reviewing-post-16-education-policy.pdf

Boles, N. 2015. Funding Allocations 2015 to 2016. Letter from Nick Boles to further education colleges. Accessed July 2015. https://www.gov.uk/government/uploads/system/ uploads/attachment data/file/447179/Minister s Termly_Letter July_2015_Final_2_to_FE_Colleges.pdf

Burkill, S., S. Rodway Dyer, and $\bar{M}$. Stone. 2008. "Lecturing in Higher Education in Further Education Settings." Journal of Further and Higher Education 32 (4): 321-331.

Byrne, M., and B. Flood. 2005. "A Study of Accounting Students' Motives, Expectations and Preparedness for Higher Education." Journal of Further and Higher Education 29 (2): $111-124$.

Cardini, A. 2006. "An Analysis of the Rhetoric and Practice of Educational Partnerships in the UK: An Arena of Complexities, Tensions and Power." Journal of Education Policy 21 (4): 393-415.

Coughlan, S. 2015. "Meltdown' Warning in FE College Finances." BBC News 20 July 2015 http://www.bbc.co.uk/news/education-33595027

Crawford, C., and W. Jin. 2014. Payback Time? Student Debt and Loan Repayments: What Will the 2012 Reforms Mean for Graduates? London: Institute for Fiscal Studies.

Creasy, R. 2013. "HE Lite: Exploring the Problematic Position of HE in FECs." Journal of Further and Higher Education 37 (1): 38-53.

DfES (Department for Education and Skills). 2003. Widening Participation in Higher Education. London: Department for Education and Skills.

Dhillon, J. K. 2007. "Trust, Shared Goals and Participation in Partnerships: Reflections of Post-16 Education and Training Providers in England." Journal of Vocational Education and Training 59 (4): 503-515.

Dhillon, J. K. 2013. "Senior Managers' Perspectives of Leading and Managing Effective, Sustainable and Successful Partnerships'." Educational Management, Leadership \& Administration 41 (6): 736-750.

Elliott, G. 2015. "Challenging Assumptions about Values, Interests and Power in Further and Higher Education Partnerships." Journal of Further and Higher Education 1-12.

Etherington, K. 2004. Becoming a Reflexive Researcher: Using Ourselves in Research. London: Jessica Kingsley.

Feather, D. 2011. "Culture of HE in FE - Exclave or Enclave?" Research in Post-Compulsory Education 16 (1): 15-30.

Greenbank, P. 2007. "From Foundation to Honours Degree: The Student Experience." Education and Training 49 (2): 91-102.

Hall, M., A. Ramsey, and J. Raven. 2004. "Changing the Learning Environment to Promote Deep Learning Approaches in First-Year Accounting Students." Accounting Education 13 (4): 489-505.

Harwood, J., and D. Harwood. 2004. "Higher Education in Further Education: Delivering Higher Education in a Further Education Context-A Study of Five South West Colleges." Journal of Further and Higher Education 28 (2): 153-164.

HESA (Higher Education Statistics Agency). 2015. Higher Education Student Enrolments and Qualifications Obtained at Higher Education Providers in the United Kingdom 2013/14. HESA SFR 210. https://www.hesa.ac.uk/sfr210. 
Kadi-Hanifi, K., O. Dagman, J. Peters, E. Snell, C. Tutton, and T. Wright. 2014. "Engaging Students and Staff with Educational Development through Appreciative Inquiry." Innovations in Education and Teaching International 51 (6): 584-594.

Knox, H. 2005. "Making the Transition from Further to Higher Education: The Impact of a Preparatory Module on Retention, Progression and Performance." Journal of Further and Higher Education 29 (2): 103-110.

Lauener, P. 2015. Changes to Funding Allocations 2015 to 2016. Skills Funding Agency. https://www.gov.uk/government/uploads/system/uploads/attachment_data/file/446922/ Funding Allocations 2015 to 2016.pdf

Leese, M. 2010. "Bridging the Gap: Supporting Student Transitions into Higher Education." Journal of Further and Higher Education 34 (2): 239-251.

Marton, F., and R. Saljo. 1976. "On Qualitative Differences in Learning. Outcome and Process." British Journal of Educational Psychology 46: 4-11.

McInnes, C. 2003. New Realities of the Student Experience: How Should Universities Respond? Paper presented at European Association for Institutional Research, University of Limerick, Ireland, 24-27 August.

Ofsted (Office for Standards in Education, Children's Services and Skills). 2015a. About Us. https://www.gov.uk/government/organisations/ofsted/about

Ofsted (Office for Standards in Education, Children's Services and Skills). 2015b. What We Do. https://www.gov.uk/government/organisations/ofsted/about\#what-we-do

Orr, K. 2013. "Cultures, Colleges and the Development of Ideas about Teaching in English Further Education." Research in Post-Compulsory Education 18 (4): 377-388.

Parry, G. 2012. "Higher Education in Further Education Colleges: A Primer." Perspectives: Policy and Practice in Higher Education 16 (4): 118-122.

Pike, A., and J. Harrison. 2011. "Crossing the FE/HE Divide: The Transition Experiences of Direct Entrants at Level 6." Journal of Further and Higher Education 35 (1): 55-67.

Playdon, J. 2015. How Much Does It Cost to Study in the UK? http://www.topuniversi ties.com/student-info/student-finance/how-much-does-it-cost-study-uk

Postlethwaite, K., and W. Maull. 2007. "Understanding Students' Changing Perceptions of Their Learning Environments in Four FE Colleges in England." Educational Review 59 (4): 429-449.

QAA (Quality Assurance Agency for Higher Education). 2015a. About QAA. http://www.qaa. ac.uk/en

QAA (Quality Assurance Agency for Higher Education). 2015b. The Quality Code: A Brief Guide. http://www.qaa.ac.uk/en/Publications/Documents/quality-code-brief-guide.pdf

Schon, D. A. 1991. The Reflective Practitioner: How Professionals Think in Action. Aldershot: Arena.

Winn, S. 2002. "Student Motivation: A Socio-Economic Perspective." Studies in Higher Education 27 (4): 445-457.

Winter, J., and H. Dismore. 2010. "Investigating the Experiences of Foundation Degree Students Progressing to an Honours Degree: An Integrated Approach." Journal of Further and Higher Education 34 (2): 253-270. 